\title{
Stability and development of Transdanubian agricultural enterprises
}

\author{
Nikoletta Göllény-Kovács - Erzsébet Péter - Gábor Pintér \\ University of Pannonia Nagykanizsa - University Center for Circular Economy \\ nikoletti.kovacs@gmail.com
}

\begin{abstract}
SUMMARY
Personal fulfilment, financial security, flexibility, relationships, information, rules - these are all hallmarks of entrepreneurship. Furthermore, one more important factor should be added to the list, which enables satisfaction resulting from reliable income and self-fulfillment: this is openness. An open mind to changes, to novelties, and to the workforce is necessary. The central question of the present research is how to effectively develop Hungarian small and medium-sized agricultural enterprises, especially in the Transdanubian region, by utilizing these factors. In addition to production, institutional and price risks, agricultural enterprises, like other sectors, are also affected by massive labour shortages and resource-intensive development objectives. In the research, primary agricultural producers, micro, small and medium-sized enterprises were surveyed through questionnaire in the second and third quarters of 2019. Using the snowball method, both the development opportunities and the risks were mapped in this sector, mostly among growers. The research results show that there is a correlation between satisfaction and development and favorable workplace relationships. These correlations were presented by demonstrating the relationship between technological development, income satisfaction, stable job creation, and the need to try new developments. However, there seems to be an invisible boundary to development in the examined field, which may stem from uncertainty, and yet, it is important to maintain development and learning activity so that the right knowledge and know-how is available to the business when needed. Since the results show that there is a lack of openness to new technologies among the farmers in the studied region, and this may pose a problem in the future in terms of meeting the expectations of precision farming, it is recommended to focus on innovation in the agricultural sector in Hungary.
\end{abstract}

Keywords: development; knowledge; human resource; agriculture; entrepreneurship

\section{INTRODUCTION}

Natural and global economic phenomena together emphasize the growing significance of risk factors directly or indirectly affecting agricultural production. Farmers must not limit their risk management strategies to eliminating or mitigating the problems caused by weather and natural phenomena; effective responses to the various professional, economic and agricultural policy challenges are crucial elements to continue successful farming. It is also necessary to examine the frequent occurrence of intertwined risk factors in Hungary, as the tightening of environmental restrictions has an impact on yield. The institutional risk associated with price subsidies can also affect price risk. Furthermore, all risk factors have an impact on the safety, well-being, and profitability of human activity (AKI, 2009).

Another key problem of the agricultural economy is that nowadays the "village" only functions as a place of residence, but in the past it also provided jobs. A solution to the problem could be to base the rural development strategy on small and medium-sized family farms, local communities and indigenous varieties, and to encourage rural tourism. In the latter case, facilitating the use of food raw materials locally and expanding tendering opportunities may help.

Competitiveness in international food production is becoming increasingly dependent on the safety and quality of food products, while effectively managing overall costs. This means industry participants need to work out effective management strategies and policies to maintain the integrity of their food supply chain $(\mathrm{Ge}$ et al., 2015). Agricultural enterprises are part of these complex value chains where the actors influence each other. Especially smaller enterprises are more dependent on the key members of the chain and more sensitive to social, economic, social barriers, regulations, access to information and financial resources. Often their own managerial abilities limit them in risk and change management, and to seize possibilities of further innovation.

The aim of the present research is to discover the opportunities of agricultural entrepreneurs affected by various risks in order to create a more stable enterprise, as well as to improve the competitiveness of domestic agriculture on a global scale.

\section{Factors determining the efficiency of agricultural enterprises}

One of the tools for efficiency is knowledge, which can be used, for example, to eliminate unnecessary costs and increase effectiveness. However, according to Prusak (1999), IBM's knowledge manager, we cannot manage knowledge itself. Nonetheless, we can create and maintain an environment that can transform the knowledge inherent in the organization into a productive force. Three interrelated things are needed so that such a system may work successfully: technologies, processes, and people. Continuous, longterm support from top-level management and an organizational culture that supports knowledge sharing are essential to initiate and keep these elements working together. In fact, it activates an organization's knowledge management system.

In parallel with international research, studies have been published in Hungary, which support that development and its maintenance may sometimes require a change of attitude, personal development and learning. As for agricultural enterprises, learning 
should not be neglected, as the availability of information and expertise can lead to significant increases in efficiency and productivity, especially when trying out more advanced technology.

The use of information technology is at least as important to efficiency as knowledge management, since both provide information for the business. For example, a 2001 survey of agricultural enterprises with more than five employees found that only one in five employees used a personal computer and $65 \%$ of farmers surveyed did not have their own website because they did not need it for their activities. Firms operating in the sector mostly keep in touch with each other in person or by telephone (Vajdáné et al., 2001).

According to a 2013 research, taking into account Hungarian agriculture, primarily arable crop production, the technical development should focus on human resources, as farmers need it the most (Tóth, 2017). This may be due to the fact that everything else is available on the market, but knowledge and knowhow as intangible assets are more difficult to access.

In their study, Popp et al. (2017) also mention that training, development, innovation, and adaptability are prerequisites for successful farming today. However, several sources prove that Hungary does not use its opportunities, innovative solutions are scarce and expertise is also incomplete, which entails additional risks.

In their research, Reszegi and Juhász (2017) hypothesize that domestic corporate growth opportunities are largely determined by the firm's basic economic characteristics, such as market share or established prices and customer relationships. A drastic change in these factors cannot be achieved overnight. Further examples include the technical base of the company, its productivity, or the knowledge and skills of the employees and the management, which also require a longer period to change.

Thus, the focus of efficiency and development is mostly on knowledge, information technology and human resources. In the following section, we will examine what can make our domestic agricultural entrepreneurs more productive and competitive.

\section{Foundations of agricultural productivity and competitiveness}

Nowadays, competitiveness is one of the most important parameters, which is difficult to quantify, but each player in the economy tries to measure it with different indicators depending on their capabilities and thus gain an advantage over the competitors. Territorial competitiveness consists of the competitiveness of enterprises and other actors in society in a given area. In addition, it includes making the area attractive as a place to live and make investments, an area of entrepreneurship with unique characteristics.

The competitiveness of local businesses can be ensured by offering cheaper, predictable energy supplies. The financial and economic sustainability of the institutions of the settlements in the region can become more stable by using locally generated energy with a competitive price. According to several national and regional spatial development concepts, the development of all regions must be based on their capabilities and strategies, strengthening their viable functions and improving their ability to attract resources. Innovative agricultural solutions can play a key role in this process (Németh, 2018; Németh and Pintér, 2014).

Furthermore, in terms of agricultural productivity, the quality of the soil is not negligible either. The 2019 research findings by Willy et al. support that low population density results in better soil quality and increased yields. In densely populated areas the soil becomes acidified, which is detrimental to plants, so maintaining soil quality requires more attention. This statement was confirmed as early as 1965 by Boserup's theory claiming that increasing population density can only be offset by intensifying sustainable agriculture. Moreover, maintaining soil quality not only increases yields but also contributes to food security (Barnes et al., 2019).

Precision crop production help build the theory of sustainable agriculture, which is based, among other things, on less material use. Precision farms sprang up in the early 1920s, when the concept of site-specific farms taking account of heterogeneity within the field emerged (Franzen and Mulla, 2015). Modern precision farms came into existence in the 1980s, when yield measuring devices, various sensors, variable rate application, and global positioning systems appeared. The first precision farms became widespread in the United States, Australia, and some European countries, and then Argentina, Brazil, and some Asian countries also incorporated new technologies into their farming processes (Fountas et al., 2005). Precision farms appeared in Hungary only after the 2000s, and their spread cannot be considered rapid (Lencsés, 2013).

Technical solutions for precision crop production include optimized mechanization, i.e., auto-guidance systems. Steering systems to minimize operational overlap, machinery telemetry, yield maps and sensor systems to collect basic data are digital tools to be applied in agriculture. In addition, input optimization using nitrogen sensors, soil samples, and map-based variable rate application is extremely important (Jóri, 2018).

By monitoring and improving the quality of soil and giving priority to local production instead of global one, the productivity and competitiveness of local businesses could be increased, which could also strengthen the position of the Hungarian agriculture in the European Union.

\section{MATERIALS AND METHODS}

As part of the empirical research, the quantitative survey was conducted using the snowball method in the second and third quarters of 2019. All the respondents were primary producers operating within agriculture or actively applying its elements, as well as managers of micro, small and medium-sized enterprises. The sample was comprised of 252 agricultural entrepreneurs. The population includes farmers raising livestock (23\%) 
and other animals (6\%), grape growers and wine producers $(18 \%)$, beekeepers $(12 \%)$, fruit growers $(10 \%)$, horticultural growers $(8 \%)$, backyard farmers $(5 \%)$, but the majority of the respondents are engaged in arable crop production (51\%).

The quantitative survey questionnaire consists of four parts: activity-related general questions, management-related questions, safety and finally demographic questions.

We highlighted four variables (income satisfaction, technological development, the need for stable job creation, the use of new technology) evaluating the answers to the questionnaire and performed a relationship analysis. In order to test the hypotheses, Likert-scale variables were used and we applied the most frequently used statistical analysis method, correlation calculation, and the SPSS statistical software package.

\section{RESULTS AND DISCUSSION}

The primary objective of the study is to explore the current economic activities in agriculture involving domestic farmers. The priorities of the research include conducting a study in the Transdanubian region with primary producers operating within agriculture, as well as with the managers of agricultural micro, small and medium-sized enterprises.

The first hypothesis of the research assumes that the desire for new developments in Hungarian agricultural enterprises is not generated by competition or to raise the current level of development, but by the feeling of security, i.e. income satisfaction.

Furthermore, as a second hypothesis, the author suggests that no matter how advanced a company's technology is - it may even utilize precision farming -, the owners may not consider it important to provide a secure livelihood for their employees. Mostly, they are affected by their own security and income satisfaction.

As a third hypothesis, the research would support the assumption that innovations and new developments do not necessarily appear in companies that already have a higher level of development, but more likely, at lower levels where there is more competition.

The conclusions of the research and the results of the hypotheses testing are presented below.

\section{First hypothesis}

A particularly important factor in the activities of agricultural entrepreneurs is the utilization of diversification, which contributes to maintaining liquidity. For example, besides crop production they can take up new activities, such as animal husbandry, additional transport or drying services, taking out insurance, machinery maintenance, and trade. When they perform several activities in parallel, if there is a problem in one area, the other can make up for the lost income. It can create or increase income satisfaction, but may require additional developments.

Thus, according to the hypothesis, the desire for new developments is not generated by the increasing competition or the current level of technological development, but by income satisfaction.

H-1: The agricultural entrepreneurs' need for technological development depends mostly on income satisfaction and not on the current (subjective) technological development

Handling multiple activities requires the management of several tasks, so the entrepreneur could ensure a more predictable operation by preparing longterm business plans. In addition, it is extremely important that the entrepreneur is aware of the production processes and is able to plan for the long term. Furthermore, digital solutions are essential to monitor costs and eliminate problems quickly. Financial stability can be further strengthened by utilizing financial and advisory services. Organizing and controlling trade would solve additional problems for them, as crop prices are sometimes unreasonably low.

The first step in confirming the hypothesis is to observe the co-movement between income satisfaction and the willingness to apply technological innovations, as shown by the correlation between the two variables known as Spearman's correlation coefficient, where $\mathrm{r}_{\text {development, }} \quad$ satisfaction $=0.397$ and $\mathrm{p}=0.000$. The entrepreneurs themselves subjectively judged their own technological development and income satisfaction. Therefore, there is a moderately strong, positive relationship between the two variables. The relationship is illustrated in Table 1.

Table 1. Demonstration of the relationship between a farmer's technological development and income satisfaction using a correlation coefficient

\begin{tabular}{ccc}
\hline & & Income satisfaction \\
\hline \multirow{2}{*}{ Technological } & Spearman's rho & 0.397 \\
development & Sig. (2-tailed) & 0 \\
& $\mathrm{~N}$ & 252 \\
\hline
\end{tabular}

Source: edited by the authors

Table 1 shows that the relationship between the two factors is positive and moderately strong $(0<0.397<1)$, i.e. there is a linear relationship between technological development and the farmer's income satisfaction.

The research revealed that our Transdanubian agricultural entrepreneurs are moderately or very satisfied with their income (197 responses) and open to new developments $(85 \%)$, and most of them engage in several activities at the same time (115 responses). We can say that they take one of the most important steps to survive in the long run: they develop their businesses. They probably do this because they are forced to, but the end result is still technical progress.

However, it is important to mention that developments, especially in a resource-intensive sector of the economy such as agriculture, require up-to-date information and knowledge, and additional substantial financial support. Technology is constantly advancing and moving towards full-scale optimization, which 
requires replacing old devices with newer, more efficient ones, and learning how to use them.

\section{Second hypothesis}

According to one of the interviewees of the research, who also has international experience, the competitive advantages of the Hungarian agriculture are the low production costs of labour-intensive processes and cheap labour. As land prices are also lower than in Western Europe and we can use highquality machinery and products in Hungary, plus farm sizes can be increased within certain limits, eliminating land fragmentation would improve the national economy. However, this would require the acquisition of land, which has strict regulations, or setting up agricultural cooperatives and farming partnerships.

Another important factor is that the tenders achieved a better effect than expected and they are also more diversified. As a result, more and more crops have to be produced in smaller and smaller areas making the spread of precision farms in Hungary inevitable. This could ensure a higher income-generating capacity and eliminate liquidity problems, as farmers cultivating a larger land have been proven to be more developed and more profitable (Lencsés et al., 2014).

Both the production area and the demand for labour would also increase for a given economy, and maintaining liquidity is also essential to ensure their stability. All in all, we can say that improving technology should not be an end in itself, but in order to create economies of scale, it is necessary to increase the land size - and to produce as many products as possible by utilizing advanced technology.

The second hypothesis therefore seeks to establish a link between entrepreneurs' income satisfaction and their desire to create a stable job, assuming that no matter how advanced a company's technology is - it might as well use precision farming -, providing a secure livelihood for the employees may not be a priority. Mostly, they are affected by their own security and income satisfaction.

H-2: It is not the current (subjective) technological development but the entrepreneurs' income satisfaction that influences their willingness to create stable jobs.

The co-movement between stable job creation and the income satisfaction of the farmers involved in the research is shown by the relationship between the two variables, i.e. Spearman's correlation coefficient, where $\mathrm{r}_{\text {satisfaction, stable job creation }}=0.408$ and $\mathrm{p}=0.000$. Therefore, there is a moderately strong, positive relationship between the two variables. The relationship is illustrated in Table 2.

It can be concluded from Table 2 that the relationship is positive and moderately strong $(0<0.408<1)$, so there is a linear relationship between the farmers' income satisfaction and their demand to create stable jobs.

As there are large areas of agricultural land in Hungary and the quality of arable land is favourable, new technologies and raw materials are available, yet the labour force is constantly decreasing, it is worth to establish long-term liquidity by utilizing production optimization (by increasing capacity or improving technology), which also brings about long-term employment.

Table 2. Demonstrating the relationship between income satisfaction and the demand to create a stable job using Spearman's correlation coefficient

\begin{tabular}{lcc}
\hline & & $\begin{array}{c}\text { Demand to create a } \\
\text { stable job }\end{array}$ \\
\hline Income & Spearman's rho & 0.408 \\
satisfaction & Sig. (2-tailed) & 0 \\
& $\mathrm{~N}$ & 252 \\
\hline
\end{tabular}

Source: edited by the authors

\section{Third hypothesis}

If we look at the development of businesses, it is necessary for a smaller business to reach the level where profitability is ensured, and then competition becomes main priority; however, experience has shown that there is a point in the development process where it is not possible to move on to the next level without knowledge and information.

In order to eliminate the problem, domestic agricultural training, professional training and demonstrations should transfer knowledge to small and medium-sized entrepreneurs. Furthermore, an optional network of advisors would be extremely useful, which could be complemented with self-organizing cooperatives and circles where experience could be shared in common forums.

In order to test the third hypothesis, we need to examine the correlation between the entrepreneurs' own assessment of their technological development and the need to try out new developments in the course of their activities. The assumption is based on the fact that the assumption that innovations and new developments do not necessarily appear in companies that already have a higher level of development, but more likely, at lower levels where there is bigger competition.

H-3: The need to try out the latest agricultural technology does not depend on the current (subjective) level of technological development used in farming

The co-movement between the level of technological development of the agricultural entrepreneurs participating in the research and their need to try out developments is shown by the correlation between the two variables known as Spearman's correlation coefficient, where $r_{\text {development, }}$ testing new developments $=-0.343$ and $\mathrm{p}=0.000$. Therefore, there is a moderately strong, negative relationship between the two variables. The relationship is illustrated in Table 3.

Table 3 reveals that the relationship between the two variables is negative and moderately strong $(0<-0.343<-1)$. Thus, as for our Transdanubian agricultural entrepreneurs, a negative relationship can be detected between technological development and the need to try out new developments. 
Table 3. Demonstration of the relationship between a farmer's technological development and the need to test new developments using Spearman's correlation coefficient

\begin{tabular}{lcc}
\hline & & $\begin{array}{c}\text { The need to test new } \\
\text { developments }\end{array}$ \\
\hline Technological & Spearman's rho & -0.343 \\
development & Sig. (2-tailed) & 0 \\
& N & 252 \\
\hline
\end{tabular}

Source: edited by the authors

Consequently, innovation is generated much more likely by competition at lower levels than by the further development of advanced enterprises. As it has been shown in the past, innovations should aim to establish and sustain economies of scale and profitability in the long term. The idea of precision farming and future opportunities in Hungary may still not be correctly reflected in the public mind.

\section{CONCLUSIONS}

The research results confirm that there is a correlation between satisfaction and development and favorable workplace relationships, which is presented by demonstrating the relationship between technological development, income satisfaction, stable job creation, and the need to try out new developments. Further results show that the majority of farmers are well capitalized, yet, the more advanced technology the Transdanubian agricultural entrepreneurs have and the more qualified they are, the less they use new improvements. There seems to be an invisible boundary to development in the region under study, which may stem from uncertainty, nevertheless, it is important to maintain development and learning activity so that the right knowledge and know-how is available to the business when needed.
Since the results show that there is a lack of openness to new technologies among the farmers in the studied region, and this may pose a problem in the future in terms of meeting the expectations of precision farming, it is recommended to focus on innovation in the agricultural sector in Hungary. Furthermore, it has also been established that farmers with long-term plans tend to struggle due to insecurity and lack of capital. The majority of the five-year plans exist along these development barriers, so it might be worth rethinking the support system to reduce vulnerability as much as possible. Indeed, research has revealed that financial stability is necessary to increase the interest in innovation, as innovation does not depend on age and education, but on material goods and a supportive environment. Besides that, to build up a financial stability is needed the access to information and financial resources.

The research results could be used in practice to show the public the importance of the economic and social role of agriculture through the generational turnover facing the sector. Furthermore, the development of domestic agricultural training would result in the increase in suitably qualified labour force, and the sector would enjoy greater popularity, which already started with the reform of agricultural higher education in 2020. Improving leadership attitudes could also be beneficial for all sectors, which could be facilitated by various forums and marketing tools. Establishing the advisory system may also develop Hungary's agriculture into a more profitable industry with widespread adoption of precision farming.

\section{ACKNOWLEDGEMENTS}

Supported by the ÚNKP-20-3 new national excellence program of the Ministry for Innovation and Technology from the source of the National Research, Development and Innovation Fund.

\section{REFERENCES}

Agricultural Economics Research Institute (2009): Risks and risk management in agriculture. Agrárgazdasági Kutató Intézet. ISBN 9789634915362

Barnes, A.P.-Soto, I.-Eory, V.-Beck, B.-Balafoutis, A.-Sánchez, B.-Vangeyte, B.- Fountas, S.-van der Wal, T.-Gómez-Barbero, M. (2019): Exploring the adoptation of precision agricultural technologies: A cross regional study of EU farmers. Land Use Policy. 80: 163-174.

Boserup, E. (1965): The Conditions of Agricultural Growth the Economics of Agrarian Change Under Population Pressure London. Earthscan Publications Ltd. 15-52.

Fountas, A.-Pedersen, S.M.-Blackmore, S. (2005): ICT in Precision - diffusion of technology, in Gelb, E.-Offer, A. (eds.): ICT in agriculture - perspective of technological innovation. Environmental Economics and Management, On-line (https://economics.agri.huji.ac.il/sites/default/files/agri_econom ics/files/gelb-pedersen-5.pdf)
Franzen, D.-Mulla, D. (2015): A history of precision farming, in Zhang, Q. (ed.): Precision agriculture technology for crop farming. London. CRC Press. London. 1-20.

Ge, H.-Gray, R.-Nolan, J. (2015): Agricultural supply chain optimization and complexity: A comparison, International Journal of Production Economics, 159: 208-220.

Jóri, J.I. (2018): Agriculture of the future, focusing on efficiency The mechanization issues of precision farming. Agrofórum Online. On-line (https://agroforum.hu/agrarhirek/gepinfo/jovomezogazdasaga-fokuszban-hatekonysag-precizios-gazdalkodasgepesitesi-kerdesei/, 2019.09.08)

Lencsés, E.-Takács, I.-Takács-György, K. (2014): Farmer's perception on precision farming technology among Hungarian farmers. Sustainability. 6: 8452-8465.

Lencsés, E. (2013): Economic evaluation of precision (site-specific) crop production, PhD thesis. SZIE-GSZDI Gödöllő

Németh, K. (2018): Locality and Sustainability: Current Issues in the Development of the Renewable Energy Industry. Veszprém. University Press of Pannonia. 144 p., ISBN: 978-963-396-113-1 
Németh, K.-Pintér, G. (2014): The pillars of regional and municipa level energy-planning processes, In: Bene, Szabolcs (eds.) $20^{\text {th }}$ Youth Scientific Forum: University of Pannonia Georgikon Faculty Keszthely. University of Pannonia Georgikon Faculty. 297-307.

Popp, J.-Hollósi, D.-Fazekas, P.-Oláh, J. (2017): Relationships between competitive agriculture, land prices and land incomegenerating capacity, Gazdálkodás, 61/ 6: 491-504.

Prusak, L. (1999): W hat's up with knowledge management? A personal view. in: Cortada, J.W.-Woods, J.A. (eds.): The knowledge management yearbook 1999- 2000. Boston. MA: Butterworth Heinemann: 3-7.
Reszegi, L.-Juhász, P. (2017): Barriers to Hungarian corporate growth. Vezetéstudomány. 48/6-7: 27-38.

Tóth, J. (2017): Demand for technology in agriculture. Gazdálkodás. 61/3: 199-206.

Vajdáné, H.P.-Zánkai, K.-Podruzsik, Sz.-Nagy, Sz. (2001): Supporting agriculture through infocommunication tools. Ipargazdasági Kutató és Tanácsadó Kft. Information Society Monitoring Studies. Budapest

Willy, D.K.-Muyanga, M.-Jayne, T. (2019): Can economic and environmental benefits associated with agricultural intensification be sustained at high population densities? A farm level empirical analysis. Land Use Policy. 81: 100-110. 